\title{
Thymoma in a 14 Month Female with Mild Pure Red Cell Aplasia
}

\author{
Tiwari $\mathbf{S}^{1}$, Bafna V $^{2}$, Shrotriya $\mathbf{S}^{3}$, Kalrao V4, Lalwani $\mathbf{S}^{5}$
}

\begin{abstract}
Thymoma is a rare case presenting in the paediatric age group. Only 30 cases have been reported so far. Our case is a 14 month old female, presented with respiratory distress. CT scan showed gross widening of superior mediastinum with a homogeneous opacity. Immunohistochemistry was suggestive of thymoma. She underwent excision of the thymic mass and is well at present.
\end{abstract}

Key words: Thymoma, Anterior mediastinal mass, Infant, Rare tumour

\section{Introduction}

The origin of thymoma is in the epithelial cells and the lymphocytic component is considered to be benign. Approximately half of the anterior mediastinal tumours in adults are thymoma. It is basically a tumour in the $4^{\text {th }}$ and $5^{\text {th }}$ decade of life and is extremely rare in childhood. Only 30 cases have been reported so far in children 2,3,4,5. Usually it is asymptomatic. If it presents with respiratory symptoms, then only it is managed surgically. The diagnosis is confirmed by immunohistochemistry of the excised specimen.

\section{The Case}

A 14 month old female child came with complaints of cough since three days and respiratory distress since one day. On Examination the child was febrile and had severe pallor. She had decreased air entry on right infra-clavicular and mammary region and the rest were normal.

Complete blood count showed microcytic hypochromic anaemia with other cell lines being normal. CXR showed gross widening of superior mediastinum with homogenous opacity involving the superior mediastinum with smooth margins completely silhouetting the mediastinal structures.

CT thorax showed large well defined isodense, diffuse enhancing anterior mediastinal mass extending in to middle mediastinum draping over the mediastinal vascular structures as well as cranial aspect of heart suggestive of neoplastic aetiology.
'Dr. Shrikant Tiwari, Paediatric Resident, ${ }^{2}$ Dr. Vibha Bafna, Assistant Professor (Pediatric Hemato-oncologist), ${ }^{3}$ Dr. Shashank Shrotriya (Pediatric Surgeon), ${ }^{4}$ Dr. Vijay Kalrao, Professor, ${ }^{5}$ Dr. Sanjay Lalwani, Professor and Head. All from the Department of Paediatrics and Department of Pediatric Surgery affiliated to Bharati Vidyapeeth Deemed University, Pune, Maharashtra, India.

\section{Address for correspondence:}

Dr. Shrikant Tiwari

E-mail: drshrikant.j.tiwari@gmail.com

\section{How to cite}

Tiwari S, Bafna V, Shrotriya S, Kalrao V, Lalwani S. Thymoma in a 14 Month Female with Mild Pure Red Cell Aplasia. J Nepal Paediatr Soc 2015;35(1):76-78.

doi: http://dx.doi.org/10.3126/jnps.v35i1.10067

This work is licensed under a Creative Commons Attribution 3.0 License.

\section{(c) (i)}

In view of unexplained aetiology for anaemia, bone marrow aspiration and biopsy was done which showed evidence of suppression of erthyroid series indicating red cell aplasia.

CT guided biopsy on morphology showed hyper cellular areas packed with lymphoid cells alternating with hypo cellular areas with loose connective tissue and few dispersed lymphoid cells suggestive of cortical thymoma type $A B$ with no evidence of malignancy.

IHC was suggestive of CD3 and LCA positive in mature lymphoid cells and CK positive in epithelial cells. TdT negative was suggestive of $A B$ type thymoma. 


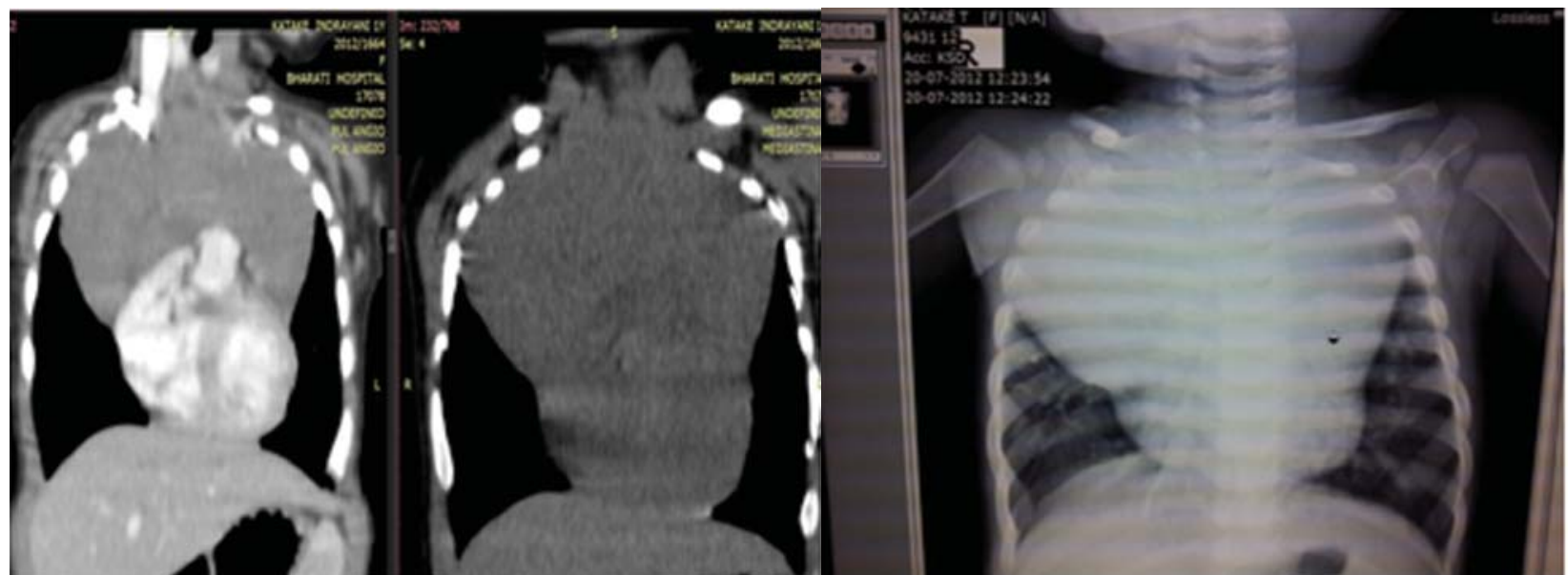

Fig 1: Large well defined isodense, diffuse enhancing anterior mediastinal mass extending in to middle mediastinum
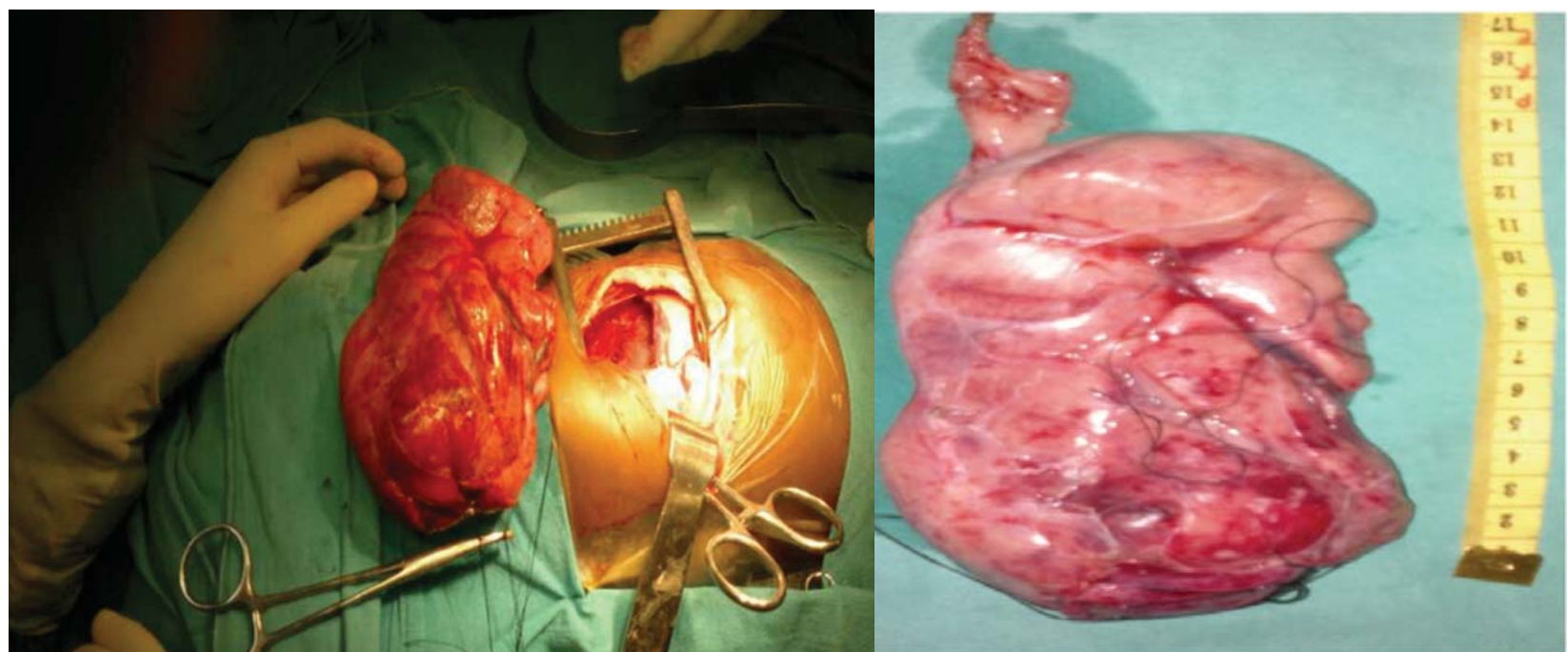

Fig 2: Well circumscribed and encapsulated mass of thymoma

On the basis of investigation, differential diagnosis of anterior mediastinal mass was made. As biopsy showed thymoma, child underwent thoracotomy with excision of the mass. Staging showed stage 1 hence no further treatment was given as per the guidelines. Child is $1 \frac{1}{2}$ years post-surgery and is well on follow up. She is growing well for her age and has no further respiratory symptoms.

\section{Discussion}

In early life the thymus is responsible for development and maturation of cell mediated immunity. Primary malignant lesions involving the anterior mediastinum include lymphomas, germ cell tumours, carcinomas, cysts, metastatic tumours, thymoma and thymic carcinomas. Around $43 \%$ of mediastinal tumours in pediatric patients occur in the anterior mediastinum but less than $1 \%$ is thymoma ${ }^{1,2,3,4,5}$.
The term thymoma is customarily used to describe the neoplasm with no overt atypia of the epithelial cells ${ }^{1}$. Traditionally histologic classification of thymoma has been described by Muller-Hermelink and Levine and Rosai (2). The WHO has recently developed a terminology based on cellular type and atypia so we have types $A, B(B 1, B 2, B 3), A B$ and $C^{2}$.

Thymoma is a slowly growing tumour and nearly half of all the patients are asymptomatic and picked up incidentally on imaging. The presenting symptoms may be cough, chest pain, superior vena cava syndrome, hoarseness and dysphagia, these patients may also have Para neoplastic disorders like myasthenia gravis, red cell aplasia, hypogammaglobulinemia, autoimmune disorders like SLE, and endocrine disorders like hyperthyroidism.

So our patient, 14 month old infant presented with thymoma of $A B$ variety with a mild degree of 
pure red cell aplasia. A radical excision of the mass was done and was assigned stage 1 according to the Masoaka and colleagues post-surgical staging system. The tumour was non-invasive and a total resection could be achieved. Radiation or chemotherapy was not indicated and presently our patient is doing well.

\section{Conclusion}

We have presented this case to highlight a rare cause of anterior mediastinal mass in an infant. With a correct approach, surgical staging and histopathological diagnosis, a good outcome can be achieved.

\section{References}

1. Unusual Cancers of Childhood Treatment for health professionals [Internet]. Bethesda: National Cancer Institute; [Date Unknown]. Available from:http:// www.cancer.gov/types/childhood-cancers/hp/ unusual-cancers-childhood pdq\#section/_106

2. Bickel Richard A. PediatricThymoma [Internet]. [Place Unknown]: [Publisher Unknown]; [Date Unknown] [Updated 2013 Nov 11; cited 2013 Dec 15]. Available from: http://emedicine.medscape. com/article/888536-overview

3. Liang $\mathrm{X}$, Lovell MA, CapocelliKE, Albano EA, Birch S, Keating AK, et al. Thymoma in children: Report of 2 cases and review of the literature. PediatrDevPathol 2010;13:202-8.

4. Rothstein DH, Voss SD, Isakoff $M$, Puder $M$. Thymoma in a child: Case report and review of literature. PediatrSurgInt2005;21(7):548-51.

5. Philip A Pizzo, David G Poplack, editors. Principles and Practice of Pediatric Oncology.5th edition. Philadelphia: Lippincott Williams and Wilkins; 2006. 